\title{
Inhibitory Effect of Elaeagnus umbellata Fractions on Melanogenesis in $\alpha$-MSH-Stimulated B16-F10 Melanoma Cells
}

\author{
Ji-Hyun Lee ${ }^{1,+}$, Bori Lee ${ }^{2,+}$, Yong-Deok Jeon ${ }^{3}$, Hyun-Woo Song ${ }^{2}$, Young-Mi Lee ${ }^{2}$, Bong-Joon Song ${ }^{4}$ \\ and Dae-Ki Kim ${ }^{1, *}$
}

check for

updates

Citation: Lee, J.-H.; Lee, B.; Jeon, Y.-D.; Song, H.-W.; Lee, Y.-M.;

Song, B.-J.; Kim, D.-K. Inhibitory

Effect of Elaeagnus umbellata Fractions

on Melanogenesis in

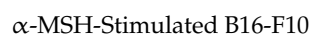

Melanoma Cells. Molecules 2021, 26,

1308. https://doi.org/10.3390/

molecules26051308

Academic Editors: Roberto Fabiani and Raffaele Capasso

Received: 18 January 2021

Accepted: 25 February 2021

Published: 1 March 2021

Publisher's Note: MDPI stays neutral with regard to jurisdictional claims in published maps and institutional affiliations.

Copyright: (c) 2021 by the authors. Licensee MDPI, Basel, Switzerland. This article is an open access article distributed under the terms and conditions of the Creative Commons Attribution (CC BY) license (https:/ / creativecommons.org/licenses/by/ $4.0 /)$.
1 Department of Immunology and Institute of Medical Science, Jeonbuk National University Medical School, 20, Geonji-ro, Deokjin-gu, Jeonju-si 54907, Jeollabuk-do, Korea; jihyunsh1211@naver.com

2 Department of Oriental Pharmacy, College of Pharmacy and Wonkwang-Oriental Medicines Research Institute, Wonkwang University, Iksan 54538, Jeonbuk, Korea; leebori1004@naver.com (B.L.); cristblack@naver.com (H.-W.S.); ymlee@wku.ac.kr (Y.-M.L.)

3 Department of Korean Pharmacy, Woosuk University, 443 Samnye-ro, Samnye-eup, Wanju-Gun 55338, Jeollabuk-do, Korea; ydjeon1211jh@woosuk.ac.kr

4 Department of Food Science and Biotechnology, Wonkwang University, Iksan 54538, Jeonbuk, Korea; twinf1@hanmail.net

* Correspondence: daekim@jbnu.ac.kr; Tel.: +82-63-2703080

+ These authors contributed equally to this work.

\begin{abstract}
When skin is exposed to UV radiation, melanocytes produce melanin. Excessive melanin production leads to skin pigmentation, which causes various cosmetic and health problems. Therefore, the development of safe, natural therapeutics that inhibit the production of melanin is necessary. Elaeagnus umbellata (EU) has long been widely used as a folk medicinal plant because of pharmacological properties that include anti-ulcer, antioxidant, and anti-inflammatory properties. In this study, we investigated the antioxidant activity and melanogenesis inhibitory effects of EU fractions in B16-F10 melanoma cells. EU fractions showed a dose-dependent increase in antioxidant activity in radical scavenging activity. In addition, we evaluated the effect of EU fractions on tyrosinase activity and melanogenesis in $\alpha$-melanocyte-stimulating hormone-induced B16-F10 melanoma cells. EU was noncytotoxic at $12.5-50 \mu \mathrm{g} / \mathrm{mL}$. EU fractions effectively inhibited tyrosinase activity and melanogenesis, suppressed the phosphorylation of CREB and ERK involved in the melanogenesis pathway, and down-regulated expression of melanogenesis-related proteins. Interestingly, the antimelanogenesis effect was most effective at a concentration of $50 \mu \mathrm{g} / \mathrm{mL} \mathrm{EU}$, and the effects of the fractions were superior to those of the extract. Therefore, our study suggests that EU has potential as a safe treatment for excessive pigmentation or as a natural ingredient in cosmetics.
\end{abstract}

Keywords: Elaeagnus umbellata; skin-whitening; antioxidant; melanogenesis; $\alpha$-MSH

\section{Introduction}

Skin color in humans depends on the amounts of melanosomes genetically present, and the degree to which these melanosomes are dispersed in the skin and is also affected by the degree of sunlight exposure and environmental pollution [1]. Melanin is a high molecular weight compound found in animals and plants and is an important pigment that determines the eye, skin, and hair color of humans. Melanogenesis refers to the production process of melanin, a major cause of pigmentation in human skin. Melanin can protect the skin from harmful UV radiation, but excessive melanin production can lead to esthetic problems, including melasma and freckles, as well as health problems, including post-inflammatory hyperpigmentation [2].

Melanin plays a crucial role in protecting the skin from various stimuli, such as UV, reactive oxygen species (ROS), and $\alpha$-melanocyte stimulating hormone ( $\alpha-\mathrm{MSH})$ [3]. When the skin is exposed to UV radiation, ROS is produced, and the skin cells generate excess melanin. This generated ROS destroys single and double stranded DNA and attacks 
protein and lipid molecules [4]. Melanin and antioxidant enzymes, such as peroxidase, glutathione, and catalase, neutralize the generated ROS to maintain a particular level $[5,6]$. However, uncontrollable excessive ROS production leads to a variety of problems, such as cancer [7]. Melanocytes are located in the basal layer of the epidermis and are modulated by tyrosinase. These cells produce melanin through melanogenesis, and factors such as microphthalmia-associated transcription factor (MITF) and tyrosinase-related protein (TRP-1) are involved in this process [8]. Tyrosinase is involved in the pathway by which L-tyrosine becomes 3,4-dihydroxyphenylalanine (DOPA), which is then converted to dopaquinone from which melanin is synthesized. Therefore, tyrosinase is an important factor that regulates melanogenesis in skin cells.

Recently, to solve the esthetic problems caused by pigmentation and pigmentary disorder caused by excess melanogenesis, many medical and cosmetic industries have focused on tyrosinase activity inhibitors [9]. Various chemicals such as arbutin, kojic acid, hydroquinone, and ascorbic acid, which are melanin synthesis inhibitors, are used as skinwhitening agents [10]. However, these substances do not penetrate the skin well and over an extended period of use can have side effects such as skin irritation, inflammation, itchiness, and pigmentation [11]. Therefore, there is a need to develop effective whitening agents that can safely treat and prevent the hyperpigmentation of human skin without irritation.

Elaeagnus umbellata (EU) is a plant that is widely distributed throughout Asia and has long been used as a folk medicinal plant because of associated pharmacological effects. Traditionally, the flowers and seeds of EU have been used for the treatment of respiratory diseases, including those affecting the heart and lungs, whereas the leaves have been used as a tonic and for treating intestinal diseases [12,13]. In addition, EU is used as a muscle relaxant, analgesic, anti-ulcer, anti-diabetic, and antipyretic agent [14]. EU ingredients have anti-cancer [15], antioxidant, and anti-inflammatory effects [16], and EU extract has an effect on skin whitening and wrinkle improvement [17]. However, studies regarding the effect of skin whitening by branches and leaves in the EU fractions have not yet been conducted. Therefore, the purpose of this study was to observe the in vitro antioxidant activity and melanogenesis inhibition of branch and leaf derived EU fractions on melanin producing B16-F10 murine melanoma cells and to confirm the potential of branch and leaf derived EU as a cosmetic skin-whitening agent.

\section{Materials and Methods}

\subsection{Materials and Reagents}

Primary antibodies for mouse anti-MITF (\#sc-25386), tyrosinase (\#sc-15341), TRP1 (\#sc-514900), TRP-2 (\#sc-74439), p-ERK (\#sc-7383), ERK 1/2 (\#sc-514302), and $\beta$-actin (\#sc-47778) were obtained from Santa Cruz Biotechnology (Santa Cruz, CA, USA). The primary anti-bodies for mouse anti-cyclic AMP (cAMP) response element-binding protein (CREB) (8763) (\#9198S) and CREB (D76D11) (\#4820S) were purchased from Cell Signaling Technology (Beverly, MA, USA); all primary antibodies were used at 1:1000 dilutions. Secondary mouse antibody for primary antibodies was purchased from Enzo Life Sciences (Farmingdale, NY, USA) and used at 1:5000 dilutions. Fetal bovine serum (FBS), Dulbecco's modified Eagle's medium (DMEM), and penicillin/streptomycin were purchased from Gibco BRL (Carlsbad, CA, USA). Most chemicals, including $\alpha$-MSH, 3-(4,5-dimethylthiazol2-yl)-2,5-diphenyl tetrazolium bromide (MTT), L-DOPA, 1,1-diphenyl-2-picryl-hydrazy (DPPH), 2, 2-azino-bis (3-ethylbenzothiazoline-6-sulfonic acid (ABTS), arbutin, and mushroom tyrosinase were purchased from Sigma-Aldrich (St. Louis, MO, USA).

\subsection{Preparation of the EU Extract and Fractions as Well as Sample Preparation}

Branches and leaves (1:1) of EU were provided by the Jeonbuk Institute for Food Bioindustry (Jeonju, Jeonbuk, Korea). EU (50 g) was ground using a blender, and EU powders were extracted with $70 \%$ ethanol for $24 \mathrm{~h}$ at room temperature. The solvent was sterile filtered through a standard sieve (Advantec MFS, Taipei, Taiwan) and evaporated under reduced pressure using a rotary evaporator (EYELA, N-1110, Tokyo, Japan). The 
extract was lyophilized using a freeze dryer (OPERON, FDU-8606, Gimpo, Korea) to remove residual ethanol and obtain $2.4 \mathrm{~g}$ (yield, 4.8\%) of EU 70\% ethanol extract (EUEE) powder. EUEE (2.4 g) was suspended in distilled water and was partitioned with ethyl acetate (EUEA, $0.19 \mathrm{~g})$ or butanol $(\mathrm{EUBu}, 0.91 \mathrm{~g})$ fractions. All extracts and fractions were stored at $4{ }^{\circ} \mathrm{C}$ until use.

\subsection{High Performance Liquid Chromatography (HPLC) Analysis}

Chromatographic analyses were conducted using an Elite Lachrom HPLC-DAD system equipped with a UV detector (Hitachi HighTechnologies Co., Tokyo, Japan). The UV detector at $260 \mathrm{~nm}$ and analytical YMC ODS-AM $(5 \mathrm{mM}, 4.6 \times 250 \mathrm{mM})$ column (Kyoto, Japan) were used for quantification based on the internal standard method. The column temperature was $35^{\circ} \mathrm{C}$, and the mobile phase flow rate was $1 \mathrm{~mL} / \mathrm{min}$. The eluent was a gradient of solvent $(\mathrm{A})=0.1 \%$ acetic acid in water and solvent $(\mathrm{B})=0.1 \%$ acetic acid in acetonitrile. The run time was $35 \mathrm{~min}$, and the gradient was as follows: $(\mathrm{A}) /(\mathrm{B})=88 / 12$ $(0 \mathrm{~min}) \rightarrow(\mathrm{A}) /(\mathrm{B})=78 / 22(0-18 \mathrm{~min}) \rightarrow(\mathrm{A}) /(\mathrm{B})=72 / 28(18-28 \mathrm{~min}) \rightarrow(\mathrm{A}) /(\mathrm{B})=62 / 38$ (28-35 $\mathrm{min})$. HPLC analysis is shown in Figure 1.
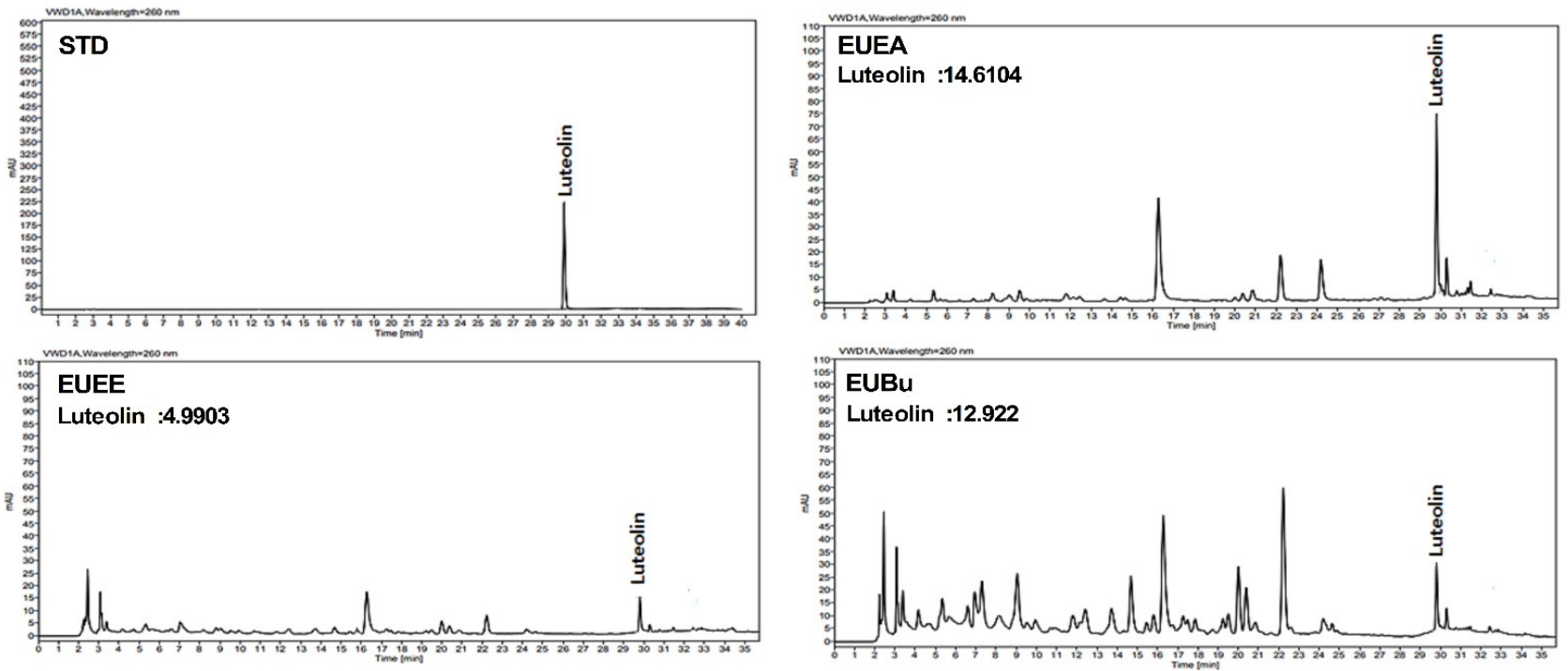

Figure 1. HPLC analysis of EUEE, EUEA, and EUBu. HPLC chromatograms of standard compound (STD) and EU extract and fraction samples. The peak in the HPLC chromatogram indicates luteolin.

\subsection{Cell Culture}

Murine melanoma B16-F10 cell line (CRL-6475) was purchased from the American Type Culture Collection (ATCC, VA, USA). Cells were cultured in DMEM supplemented with $10 \%$ heat-activated FBS and $1 \%$ streptomycin $(100 \mu \mathrm{g} / \mathrm{mL}) /$ penicillin $(100$ units $/ \mathrm{mL})$. B16-F10 cells were incubated in humidified $5 \% \mathrm{CO}_{2}$ at $37^{\circ} \mathrm{C}$.

\subsection{Cell Viability Assay}

The cytotoxicity of the samples was evaluated using the MTT assay. B16-F10 melanoma cells $\left(1 \times 10^{4}\right.$ cells /well) were cultured in a 96-well plate and incubated with various concentrations of extract and fractions $(12.5,25,50$, and $100 \mu \mathrm{g} / \mathrm{mL})$ or arbutin $(100 \mu \mathrm{g} / \mathrm{mL})$ for $24 \mathrm{~h}$ at $37^{\circ} \mathrm{C}$. After incubation, $500 \mu \mathrm{g} / \mathrm{mL}$ MTT solution was added to the wells, and the plate was further incubated for $4 \mathrm{~h}$ at $37^{\circ} \mathrm{C}$. Then, the media of each well was removed, and $200 \mu \mathrm{L}$ dimethyl sulfoxide (DMSO) was added to solubilize the formazan crystals. The absorbance of the plate was detected at $570 \mathrm{~nm}$ on a microplate reader (Synergy HTX Multi-Mode Reader, BioTek, Winooski, VT, USA). 


\subsection{DPPH Radical Scavenging Activity}

The DPPH radical scavenging activity of the EU extract and fractions was confirmed by measuring the reducing power of DPPH radicals in each sample. Various concentrations $(12.5,25$, and $50 \mu \mathrm{g} / \mathrm{mL})$ of EU extract and fractions or $20 \mu \mathrm{g} / \mathrm{mL}$ of ascorbic acid (positive control) at $500 \mu \mathrm{L}$ were added to $2 \mathrm{~mL}$ of $0.15 \mathrm{mM}$ DPPH solution. The solution was vortexed for $10 \mathrm{~s}$ to ensure thorough mixing and was incubated for $30 \mathrm{~min}$ at room temperature in the dark. The absorbance of the mixture was then measured at $517 \mathrm{~nm}$ using a microplate reader (Biotek, Winooski, VT, USA).

\subsection{ABTS Radical Scavenging Assay}

The ABTS radical scavenging solution was prepared by mixing $7.4 \mathrm{mM}$ of ABTS solution and $2.6 \mathrm{mM}$ of potassium persulfate at a ratio of 1:1 (pH 7.4), and reacting the solution at room temperature for $24 \mathrm{~h}$. The ABTS solution was then adjusted to an absorbance of $0.70 \pm 0.03$ at $732 \mathrm{~nm}$. Each $10 \mu \mathrm{L}$ sample was reacted with $190 \mu \mathrm{L}$ of ABTS solution for $10 \mathrm{~min}$ at room temperature, and absorbance was measured at $732 \mathrm{~nm}$ using a microplate reader (Biotek, Winooski, VT, USA).

\subsection{Mushroom Tyrosinase Inhibition Activity}

To analyze the inhibitory activity of tyrosinase, which plays a crucial role in melanogenesis, mushroom tyrosinase and L-DOPA substrate were used. First, $150 \mu \mathrm{L}$ of $0.1 \mathrm{M}$ phosphate buffer ( $\mathrm{pH}$ 6.8), $20 \mu \mathrm{L}$ of $5 \mathrm{mM}$ L-DOPA solution, and $20 \mu \mathrm{L}$ of the various concentrations of EU extract and fractions were sequentially added, and $100 \mu \mathrm{L}$ of $250 \mathrm{U} / \mathrm{mL}$ mushroom tyrosinase was added to initiate the reaction. The mixtures were incubated at $37^{\circ} \mathrm{C}$ for $10 \mathrm{~min}$ and the absorbance was measured at $475 \mathrm{~nm}$ using a microplate reader (Biotek, Winooski, VT, USA). The tyrosinase inhibition activity was calculated using the following formula:

$$
\text { Inhibition activity }(\%)=(1-(\text { sample OD-blank OD }) /(\text { control OD-blank OD })) \times 100
$$

\subsection{Determination of Cellular Tyrosinase Activity}

B16-F10 melanoma cells were seeded at a density of $1 \times 10^{5}$ cells/well in six-well plates containing $2 \mathrm{~mL}$ of DMEM. Six groups were established: control group, non-treated; $\alpha$-MSH group, $100 \mathrm{nM} \alpha$-MSH only; arbutin group, $\alpha$-MSH and arbutin $(10 \mathrm{mM})$; EUEE group, $\alpha$-MSH and EUEE extract $(12.5,25$, and $50 \mu \mathrm{g} / \mathrm{mL})$; EUEA group, $\alpha-\mathrm{MSH}$ and EUEA fractions $(12.5,25$, and $50 \mu \mathrm{g} / \mathrm{mL})$; and EUBu group, $\alpha$-MSH and EUBu fractions $(12.5,25$, and $50 \mu \mathrm{g} / \mathrm{mL})$. Six-well plates were incubated overnight at $37^{\circ} \mathrm{C}$ in a $5 \% \mathrm{CO}_{2}$ incubator. Then, cells were exposed to $\alpha$-MSH $(100 \mathrm{nM})$ for $48 \mathrm{~h}$ and treated with various concentrations of EUEE, EUEA, and EUBu or arbutin $(10 \mathrm{mM})$ for $24 \mathrm{~h}$. Cells were washed with phosphate-buffered saline (PBS) three times and lysed. The lysate was centrifuged at $16,000 \times g$ for $20 \mathrm{~min}$. Next, the protein content of each lysate was determined using the BCA Protein Assay Kit (Thermo Scientific, Vantaa, Finland). Protein levels were then adjusted to $20 \mu \mathrm{g}$ in all samples. Lysates $(100 \mu \mathrm{L})$ containing $2.5 \mathrm{mM}$ of L-DOPA in $0.1 \mathrm{M}$ phosphate buffer was transferred to wells in a 96-well plate and incubated for $1 \mathrm{~h}$ at $37^{\circ} \mathrm{C}$. The absorbance of the lysates was measured at $475 \mathrm{~nm}$ using a microplate reader (Biotek, Winooski, VT, USA). The intercellular tyrosinase activity was calculated using the following formula:

$$
\text { Tyrosinase activity }(\%)=\left(\mathrm{OD}_{\mathrm{s}}-\mathrm{OD}_{\mathrm{b}}\right) / \text { Control } \times 100
$$

$\mathrm{OD}_{\mathrm{s}}$ represents the absorbance of the sample and $\mathrm{OD}_{\mathrm{b}}$ represents the absorbance of the control. Arbutin was used as the standard. 


\subsection{Measurement of Melanin Contents}

To determine the amount of melanin in B16-F10 cells, these were seeded in a 24-well plate at a density of $2 \times 10^{4}$ cells/well and incubated for $24 \mathrm{~h}$ in DMEM with $10 \%$ FBS. B16-F10 cells were pretreated with various concentrations of EUEE, EUEA, and EUBu $(12.5,25$, and $50 \mu \mathrm{g} / \mathrm{mL})$ and positive control arbutin $(10 \mathrm{mM})$ for $1 \mathrm{~h}$, then reacted with $100 \mathrm{nM}$ of $\alpha$-MSH for an additional $72 \mathrm{~h}$. Afterward, cells were harvested after washing with PBS. The pellet obtained by centrifugation $(12,000 \times g, 10 \mathrm{~min})$ was lysed in $1 \mathrm{~N} \mathrm{NaOH}$ containing $10 \%$ DMSO at $90{ }^{\circ} \mathrm{C}$ for $30 \mathrm{~min}$. The melanin content of each well was measured at $405 \mathrm{~nm}$ using a microplate reader (Biotek, Winooski, VT, USA). To determine the amount of melanin, the total amounts produced during the experiment were regarded as the standard $(100 \%)$, and the inhibition rate of each extract and fraction treatment group was determined in proportion to this standard.

\subsection{Western Blot Analysis}

The B16-F10 murine melanoma cells $\left(1 \times 10^{6}\right.$ cells $/$ well $)$ were cultured in $6 \mathrm{~cm}$ dishes and incubated overnight at $37^{\circ} \mathrm{C}$, and cells were pretreated with $\alpha$-MSH $(10 \mu \mathrm{M})$ for $24 \mathrm{~h}$. Then, cells were treated with various concentrations $(12.5,25$, and $50 \mu \mathrm{g} / \mathrm{mL})$ of EU extract and fractions or $100 \mu \mathrm{g} / \mathrm{mL}$ arbutin for $24 \mathrm{~h}$. Cells were harvested with PBS then centrifuged at $12,000 \times g$ for $15 \mathrm{~min}$ at $4{ }^{\circ} \mathrm{C}$. After removing the supernatant, cells were lysed using ice-cold Pro-prep protein lysis buffer with the addition of $1 \%$ protease and phosphatase inhibitors, and kept on ice for $40 \mathrm{~min}$. The fractionated proteins were quantified using the Bradford protein assay. Equal amounts of proteins $(25 \mu \mathrm{g})$ were loaded and separated by $8 \%$ or $10 \%$ sodium dodecyl sulfatepolyacrylamide gel electrophoresis and transferred to a polyvinylidene fluoride (PVDF) membrane. The PVDF membranes were blocked with 5\% skim milk in Tris-buffered saline (TBS) with $0.1 \%$ Tween 20 (TBS-T) buffer for $1 \mathrm{~h}$ at room temperature, and incubated with specific primary antibodies against p-CREB, CREB, p-ERK, ERK, MITF, TRP-1, TRP-2, tyrosinase, and $\beta$-actin overnight at $4{ }^{\circ} \mathrm{C}$. Afterward, the membranes were rinsed with TBS-T buffer three times for $10 \mathrm{~min}$ and reacted for $2 \mathrm{~h}$ with horseradish peroxidase-conjugated secondary antibody at room temperature. Membranes were rerinsed with TBS-T buffer five times and proteins were detected with enhanced chemiluminescence solution. The band images were obtained using a Davinch-In vivo and western imaging system (Davinch-K, Seoul, Korea).

\subsection{Statistical Analysis}

All values are presented as means \pm S.E.M. (standard error of the mean) of at least three independent experiments and GraphPad Prism software 5.0 (GraphPad, San Diego, CA, USA) was used for statistical analysis. One way analysis of variance followed by Bonferroni post hoc analysis was used to compare the statistical differences between groups. A $p$-value less than $0.05(p<0.05)$ was considered statistically significant.

\section{Results}

\subsection{HPLC Analysis of EU}

The final yields (\%) of EUEE, EUEA, and EUBu were $4.8 \%, 0.18 \%$, and $1.82 \%$, respectively based on the fresh weight. HPLC was used to analyze the content of luteolin, an indicator compound of EU extract and fractions. Compared with the peak of the standard component, the peak of luteolin in the EU extract and fractions was confirmed. The concentration of luteolin in EUEE, EUEA, and EUBu was 499.03, 1948.05, and $994.00 \mathrm{mg} / \mathrm{mL}$, respectively (Figure 1).

\subsection{The Effect of EU on Antioxidant Activity and Tyrosinase Inhibitory Activity}

The antioxidant activities of the various concentrations of EUEE, EUEA, and EUBu were measured using the DPPH/ABTS assay. The DPPH and ABTS radical scavenging activities of EUEE, EUEA, and EUBu increased in a dose-dependent manner (Figure 2A,B), with ascorbic acid as a positive control. The DPPH and ABTS radical scavenging activities 
at $50 \mu \mathrm{g} / \mathrm{mL}$ of the EU extract and fractions were both higher, showing similar results to the positive control, ascorbic acid. To measure the inhibitory effect of melanogenesismediated enzymes in the EU extract and fractions, a mushroom tyrosinase inhibition assay was performed (Figure 2C) with L-DOPA as a substrate under cell-free conditions. The results showed that tyrosinase activity was inhibited by the EU extract and fractions in a dose-dependent manner. In particular, the tyrosinase inhibitory activity of $50 \mu \mathrm{g} / \mathrm{mL}$ of EU extract and fractions showed similar results to arbutin. Therefore, the tyrosinase inhibitory effect of EU is related to the oxidation of L-DOPA to DOPA quinone in melanogenesis. Overall, the EU fractions had a greater antioxidant and tyrosinase inhibitory effect than that of the extract. In addition, the EU fractions, especially EUBu, began to exhibit similar effects to the positive control group at a dose of $25 \mu \mathrm{g} / \mathrm{mL}$.

A
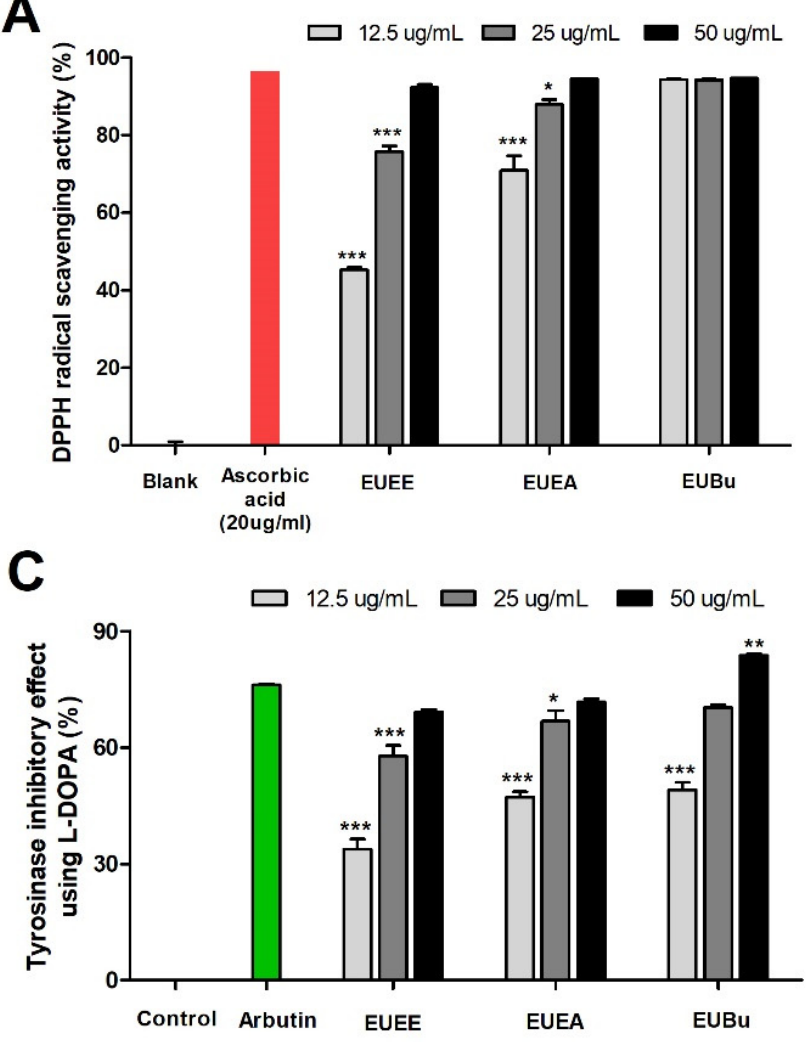

B

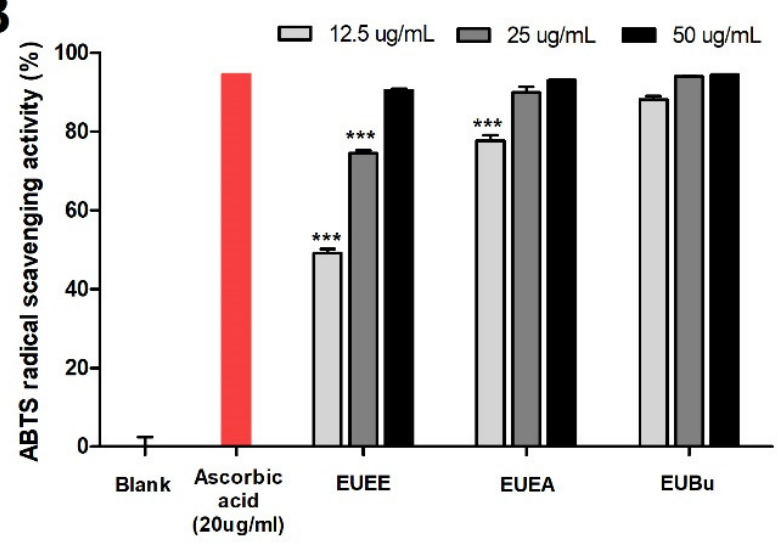

Figure 2. Antioxidant activities and mushroom tyrosinase inhibition activity of EU. Radical scavenging activity of DPPH (A) and ABTS (B) of EU extract and fractions. Ascorbic acid $(20 \mu \mathrm{g} / \mathrm{mL})$ was used as a positive control. The tyrosinase inhibitory effect using L-DOPA of EU extract and fractions (C). Arbutin (10 mM) was used as a positive control. All graphs show per centages of control, and data are expressed as means \pm S.E.M. $(n=3)$. Statistical significance was set at ${ }^{*} p<0.05$, ${ }^{* *} p<0.01$ and ${ }^{* * *} p<0.001$ when compared with the ascorbic acid or arbutin group.

\subsection{The Effect of EU on B16-F10 Cell Viability}

To assess the cell cytotoxicity of EU, B16-F10 melanoma cells were treated with various concentrations $(12.5,25,50$, and $100 \mu \mathrm{g} / \mathrm{mL})$ of EU extract and fractions for $24 \mathrm{~h}$, and cell viability was analyzed by MTT assay. The results are shown as the percentage of cell viability relative to the control. The EU extract and fractions were not cytotoxic in the tested concentration range of $12.5-50 \mu \mathrm{g} / \mathrm{mL}$ to B16-F10 cells. However, cytotoxicity was confirmed in B16-F10 cells at a concentration of $100 \mu \mathrm{g} / \mathrm{mL}$ of the EU fractions (EUEA and EUBu) (Figure 3). Therefore, subsequent experiments were conducted using concentrations of $12.5,25$, and $50 \mu \mathrm{g} / \mathrm{mL}$ of EU extract and fractions. 


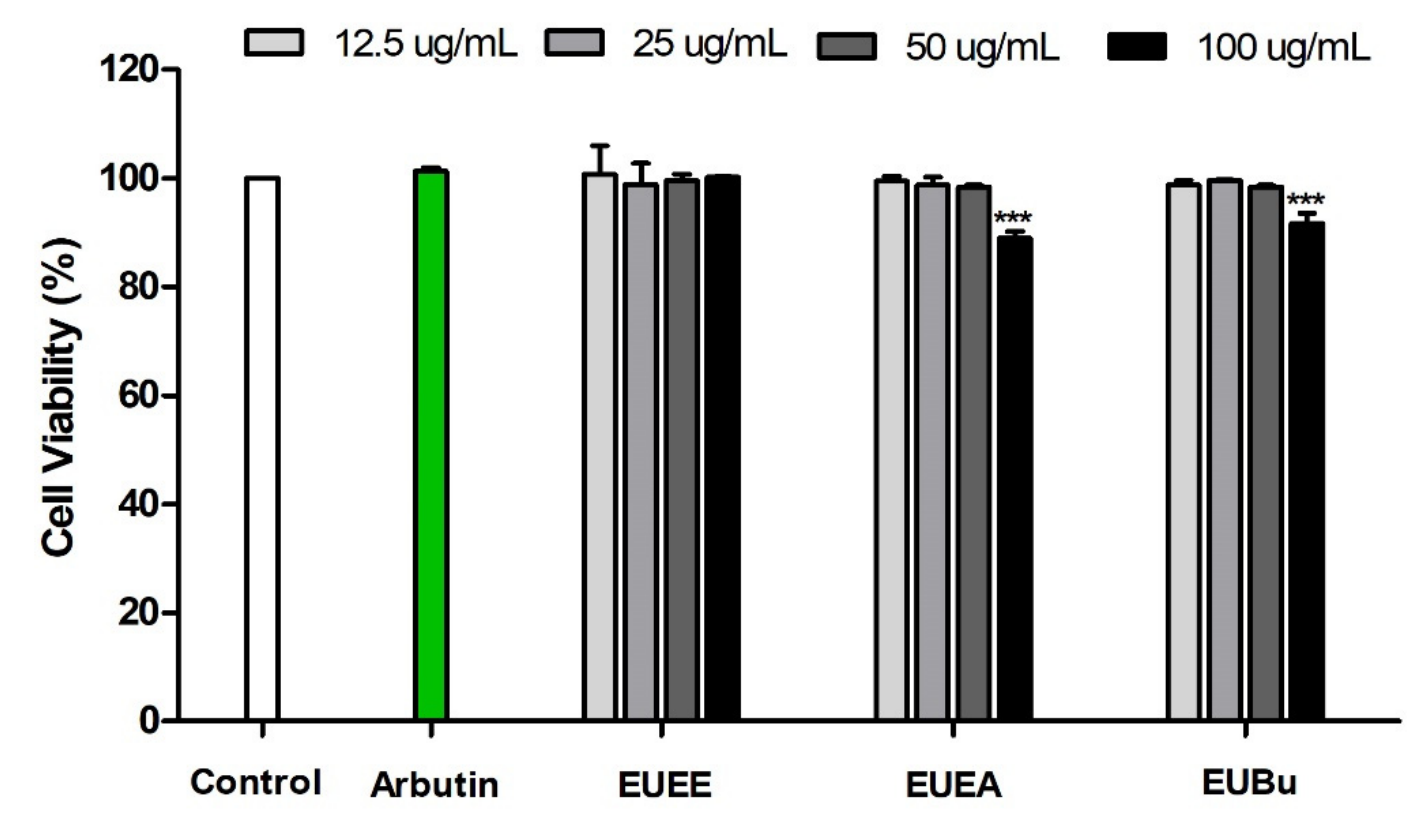

Figure 3. Cell viability of EU. Cell viability in B16-F10 melanoma cells of EUEE, EUEA, and EUBu. All graphs show percentages of control, and data expressed as means \pm S.E.M. $(\mathrm{n}=3)$. Statistical significance was set at $* * * p<0.001$ when compared with the control.

\subsection{The Effect of EU on Melanin Synthesis}

To determine the anti-melanogenic effect of EU, the inhibitory effect of EU extract and fractions on melanin synthesis were examined in B16-F10 cells. The B16-F10 cells were treated with the EU extract and fractions at $12.5,25$, and $50 \mu \mathrm{g} / \mathrm{mL}$ or with arbutin at $10 \mathrm{mM}$ for $1 \mathrm{~h}$ and were then stimulated with $\alpha-\mathrm{MSH}(100 \mathrm{mM})$ for $72 \mathrm{~h}$. The melanin content increased by $305.44 \%$ when stimulated with $\alpha$-MSH compared with that of the control (Figure 4A). However, the EU-treated groups at a concentration of $50 \mu \mathrm{g} / \mathrm{mL}$ had significantly reduced melanin content compared with that of the $\alpha$-MSH-only stimulated group, and the results were similar to those of the control group. In addition, compared with that of the arbutin positive control, the EU fractions at a concentration of $50 \mu \mathrm{g} / \mathrm{mL}$ exhibited a lower level of melanin production. Consistent with these results, as the concentrations of EU extract and fractions increased, the inhibition rate of melanin synthesis in B16-F10 cells increased (Figure 4B). In particular, the inhibition rate of melanin synthesis in the EU fractions at a concentration of $50 \mu \mathrm{g} / \mathrm{mL}$ was significantly higher than that of arbutin. Therefore, the EU fractions had a significant dose-dependent inhibitory effect on melanin synthesis in B16-F10 melanoma cells.

\subsection{The Effect of EU on Melanin Synthesis and Cellular Tyrosinase Activity}

We confirmed the effect of EU extract and fractions on intracellular tyrosinase activity involved in the mechanism of melanogenesis in B16-F10 melanoma cells. All groups, except the control, were stimulated with $\alpha$-MSH $(100 \mathrm{nM})$ for $48 \mathrm{~h}$ then treated with various concentrations of EU extract and fractions $(12.5,25$, and $50 \mu \mathrm{g} / \mathrm{mL})$ or arbutin $(10 \mathrm{mM})$ for $24 \mathrm{~h}$. As a result, EU extract and fractions significantly inhibited $\alpha$-MSH-induced tyrosinase activity in B16-F10 cells in a dose-dependent manner (Figure $4 \mathrm{C}$ ). Intracellular tyrosinase activity increased by $251.00 \%$ when stimulated with $\alpha-\mathrm{MSH}$ compared with that of the control. However, the EU-treated groups at a concentration of $50 \mu \mathrm{g} / \mathrm{mL}$ significantly decreased tyrosinase activity compared with that of the $\alpha-\mathrm{MSH}$ only stimulated group. Thus, tyrosinase activity was inhibited in a dose-dependent manner by EU treatment in B16-F10 cells, and the effect was particularly strong at a concentration of $50 \mu \mathrm{g} / \mathrm{mL}$. The inhibition of tyrosinase activity by EUEE at a concentration of $50 \mu \mathrm{g} / \mathrm{mL}$ was lower than that of arbutin (85.13\%), whereas inhibition of tyrosinase 
activity of EU fractions (EUEA and EUBu) was higher than that of arbutin (121.99 and $128.11 \%$, respectively). Consistent with these results, as the concentrations of EU extract and fractions increased, the inhibition rate of intracellular tyrosinase activity in B16-F10 cells increased (Figure 4D).
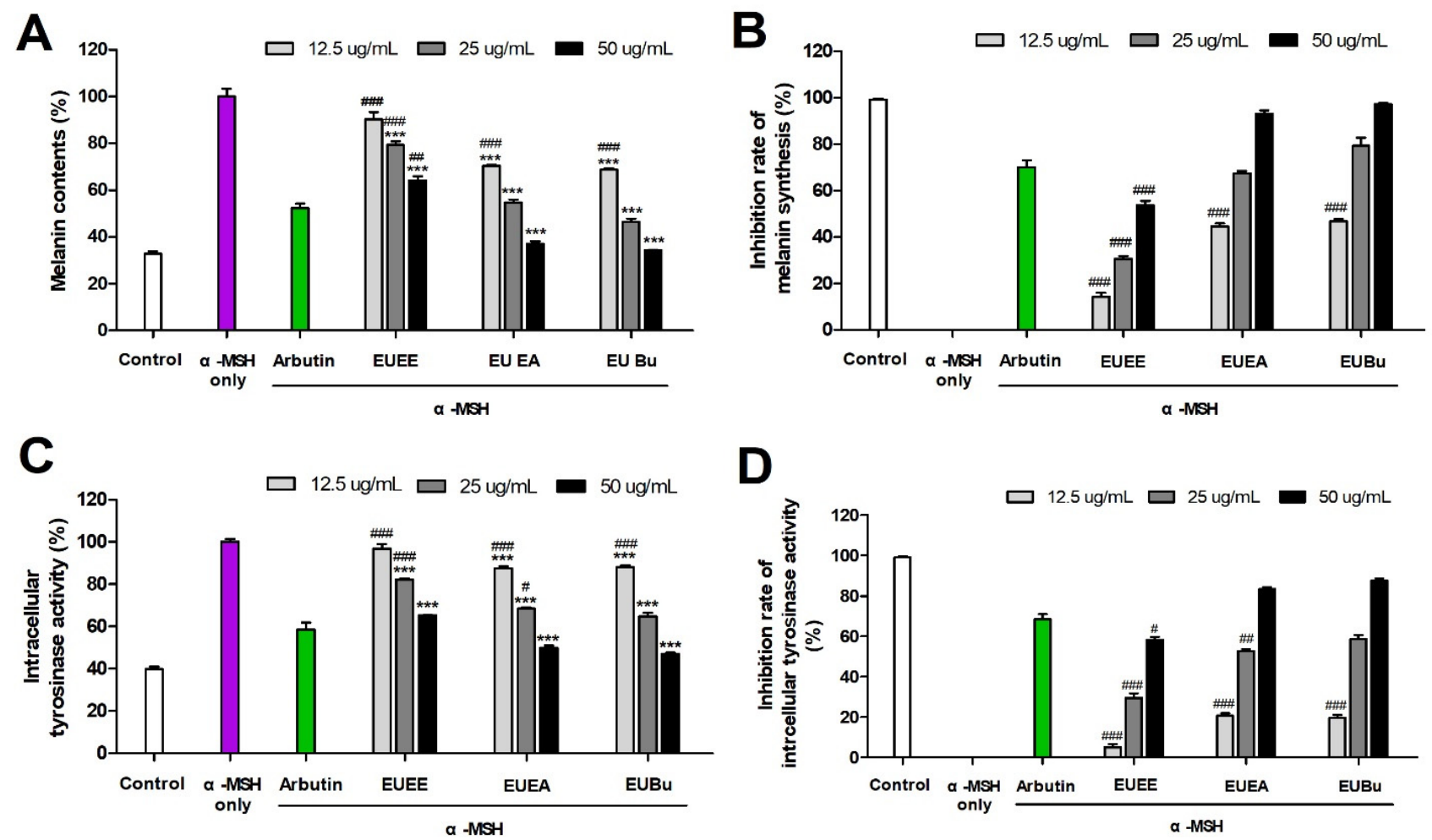

Figure 4. Melanin synthesis and cellular tyrosinase activities of EU. Melanin contents of EU extract and fractions in B16-F10 melanoma cells (A). Inhibition rate of melanin synthesis of EU extract and fractions in B16-F10 melanoma cells (B). Intracellular tyrosinase activity of EU extract and fractions in B16-F10 melanoma cells (C). Inhibition rate of intracellular tyrosinase activity of EU extract and fractions in B16-F10 melanoma cells (D). Results (A,C) are presented as percentages based on the $\alpha$-MSH group. Results (B,D) are presented as percentages based on the control group. Data are expressed as the means \pm S.E.M. $(\mathrm{n}=3)$. Statistical significance was set at ${ }^{* * *} p<0.001$ when compared with the $\alpha$-MSH-stimulated B16-F10 cells, and ${ }^{\#} p<0.05,{ }^{\# \#} p<0.01$, and ${ }^{\# \# \#} p<0.001$ compared with the arbutin group.

\subsection{The Effect of EU on Melanogenesis-Related CREB and ERK Proteins Expression}

Melanogenesis protects human skin from various external stimuli, and various mechanisms are involved in this process. $\alpha-\mathrm{MSH}$, a hormone involved in the first stage of melanogenesis, stimulates melanocytes to phosphorylate CREB and ERK, inducing the synthesis of down-signal proteins associated with melanogenesis [18]. In this study, we investigated the melanogenesis-regulated proteins, including CREB and ERK, to determine the melanogenesis inhibitory mechanism of EU on $\alpha$-MSH-induced melanin synthesis in B16-F10 melanoma cells. As a result, we confirmed that CREB and ERK phosphorylation significantly increased when B16-F10 cells were stimulated with $\alpha$-MSH. However, when cells were treated with EU extract and fractions, $\alpha$-MSH-induced phosphorylation was suppressed in a dose-dependent manner. In particular, it can be seen that the EU extract and fractions of $50 \mu \mathrm{g} / \mathrm{mL}$ concentration are the most effective among various treatment concentrations (Figure 5A-D). 

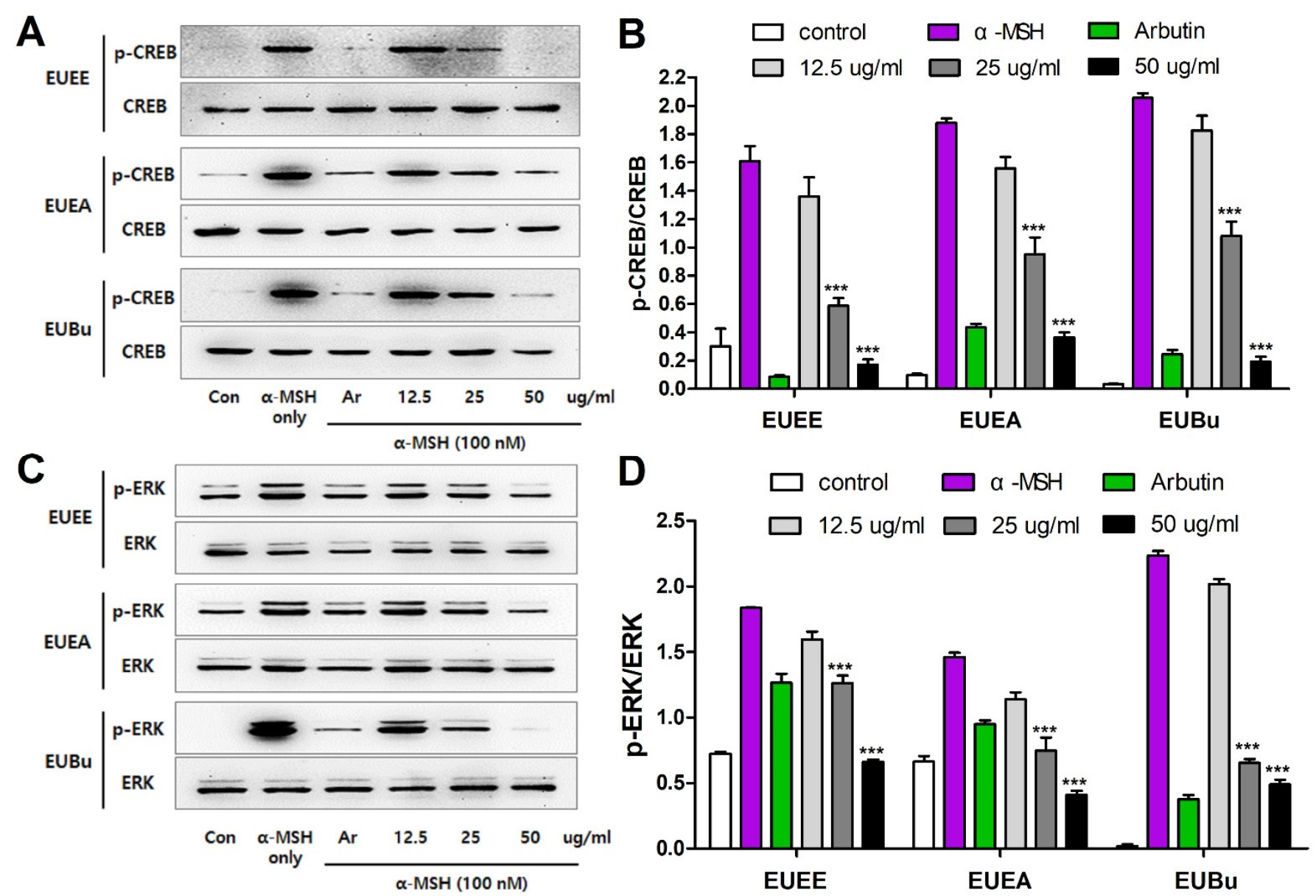

Figure 5. Inhibitory effect of EU on melanogenesis-related CREB and ERK protein expression. Representative western blotting band image of p-CREB and CREB (A) and p-ERK and ERK (C). Using the GelQuantNET program, the relative intensity of the western blotting band is shown in the following bar graphs: p-CREB/CREB (B) and p-ERK/ERK (D). Data are expressed as the mean \pm S.E.M. $(n=3)$. Statistical significance was set at ${ }^{* * *} p<0.001$ when compared with the $\alpha$-MSH-stimulated B16-F10 cells.

\subsection{The Effect of EU on Melanogenesis-Related MITF, TRP-1, TRP-2, and Tyrosinase Proteins Expression}

To investigate whether the EU extract and fractions affect the expression of melanogenesisrelated proteins induced by $\alpha$-MSH, western blotting was performed to assess the expression of MITF, TRP-1, TRP-2, and tyrosinase proteins. Levels of all the melanogenesis-related proteins were significantly increased by $\alpha-\mathrm{MSH}$ stimulation, but EU extract and fractions effectively suppressed the expression of MITF, TRP-1, TRP-2, and tyrosinase proteins in $\alpha$-MSH-stimulated B16-F10 cells (Figure 6). Consistent with the previous results, especially with most of the EU extracts and fractions at $50 \mu \mathrm{g} / \mathrm{mL}$, expression of these proteins was more inhibited than that found following treatment with positive control arbutin. In addition, the treatment with EU fractions induced a greater effect at the same concentration compared with that of the EU extract. 


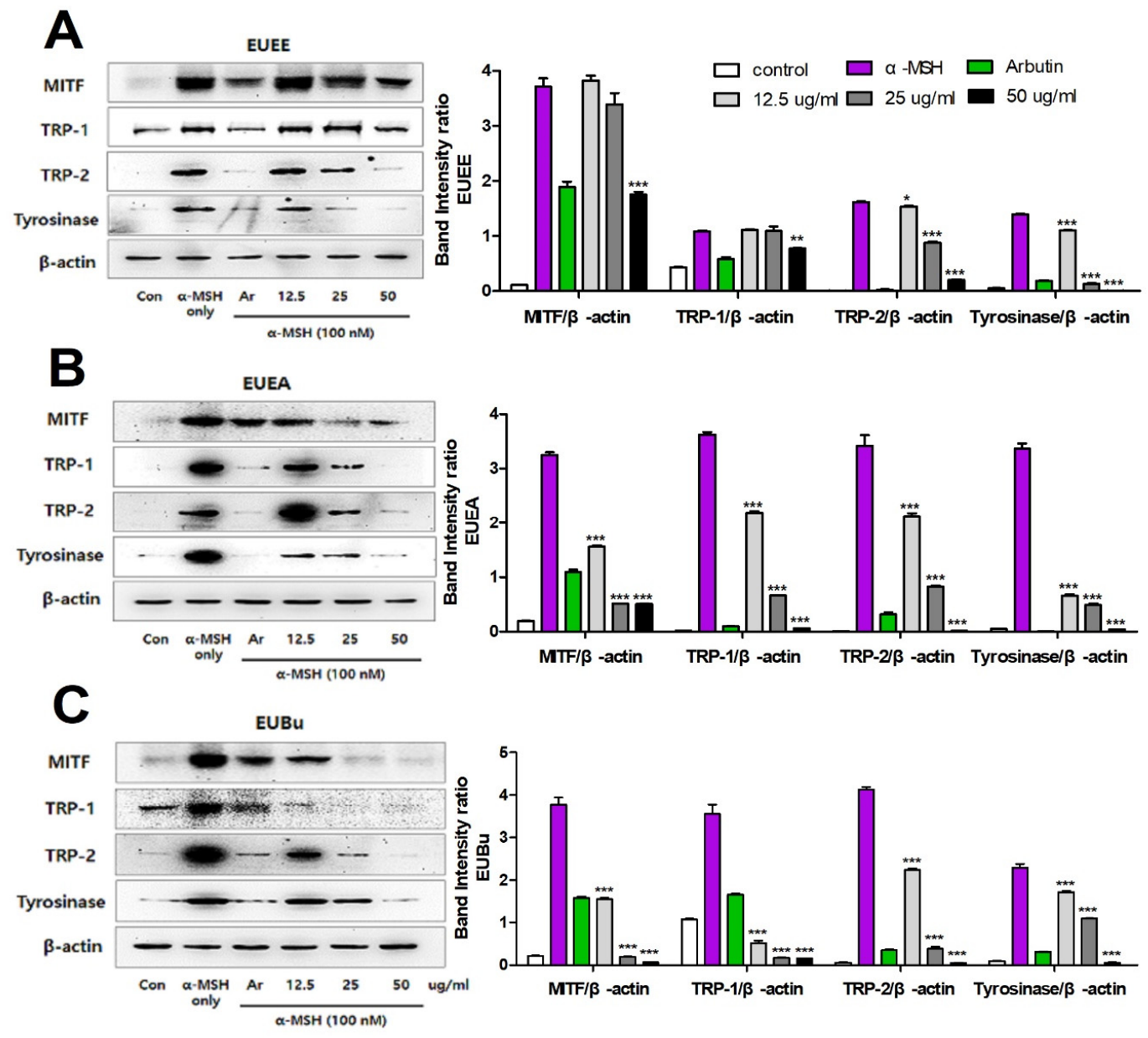

Figure 6. Inhibitory effect of EU on melanogenesis-related MITF, TRP-1, TRP-2, and tyrosinase proteins expression. Representative western blotting band image of MITF, TRP-1, TRP-2, and tyrosinase of EUEE (A), EUEA (B), and EUBu (C). Using the GelQuantNET program, the relative intensity of the western blotting band is shown as the following bar graph; MITF/ $\beta$-actin, TRP-1/ $\beta$-actin, TRP-2/ $\beta$-actin, and tyrosinase $/ \beta$-actin. $\beta$-actin was used as the internal control of western blotting. Data are expressed as the means \pm S.E.M. $(\mathrm{n}=3)$. Statistical significance was set at ${ }^{*} p<0.05,{ }^{* *} p<0.01$, and ${ }^{* * *} p<0.001$ when compared with the $\alpha$-MSH-stimulated B16-F10 cells.

\section{Discussion}

Melanocytes are located in the base layer of skin, and the degree of melanin synthesis in melanocytes determines the color of human skin [19]. Melanin is a skin pigment protects skin by reducing the amount of ROS generated by harmful ultraviolet rays. When the skin is exposed to UV radiation, $\alpha-\mathrm{MSH}$, which stimulates melanocytes, is activated, and melanocytes produce melanin [20]. However, excessive melanin production can cause pigmentation on the skin, causing esthetic problems.

Binding of $\alpha$-MSH to melanocyte receptor melanocyte-specific melanocortin-1 receptor (MC1R) activates signaling protein adenylate cyclase and increases the intracellular levels of cAMP [21]. As the level of cAMP in melanocytes increases, the CREB and ERK signaling pathways that promote the production of proteins involved in melanogenesis are activated. [18,22]. This activated CREB and ERK signaling pathway up-regulates expression of MITF and subsequently promotes the expression of TRP-1, TRP-2, and tyrosinase [23]. MITF is a transcription factor for tyrosinase regulation and plays a central role in regulating melanin synthesis, including regulating the proliferation, differentiation, and survival of melanocytes [24]. This protein not only regulates melanogenesis by regulating sub-proteins, including TRP-1, TRP-2, and tyrosinase, but is also involved in regulating cell cycle progression [25]. Taken together, $\alpha$-MSH-MC1R binding caused by external stimulation, such as 
UV radiation, mainly activates CREB and ERK signaling pathways in melanocytes, thereby increasing the expression of MITF, TRP-1, TRP-2, and tyrosinase proteins to induce the production of melanin. Therefore, inhibition of this process may result in the inhibition of melanin synthesis in melanocytes.

At present, the various skin whitening agents including hydroquinone and hydrocortisone in use are mostly harmful chemicals, and long-term use can cause side effects, including skin irritation, and itchiness [1,26-28]. Therefore, it is necessary to focus on the development of safe and effective natural skin-whitening agents with minimal side effects like EU [29].

In this study, we investigated how EU fractions inhibit melanin synthesis processes and reduce the production of melanin, resulting in the skin whitening effect in B16-F10 melanoma cells.

Since oxidative stress caused by UV radiation induces the deposition of melanin pigments, radical scavenging activity and inhibition of ROS activity are effective in suppressing melanogenesis, and natural products with such antioxidant activity can have excellent whitening effects [30,31]. Therefore, we first investigated the antioxidant activity of EU extract and fractions in B16/F10 melanoma cells using DPPH and ABTS assays, which are common and simple methods for analyzing the antioxidant activity of plants in vitro. DPPH is a stable free radical and is used to analyze the radical scavenging activity of hydrophobic compounds using reducing agents, such as ascorbic acid and tocopherol. The ABTS assay can measure radical scavenging activity for hydrophobic and hydrophilic compounds, chain breaking antioxidants, and hydrogen-donating antioxidants [24]. We confirmed the high DPPH and ABTS radical scavenging activities of EU extracts and fractions. In particular, the effects were strongest at a concentration of $50 \mu \mathrm{g} / \mathrm{mL}$, and the EU fractions had superior antioxidant activity compared with that of the extract.

Tyrosinase is a major enzyme involved in melanogenesis, and many skin-whitening agents are primarily tyrosinase inhibitors. Therefore, we examined the effect of EU fractions on tyrosinase activity, which promotes melanogenesis. We confirmed the inhibitory effect of L-DOPA on cellular tyrosinase activity to determine whether EU ex-tract and fractions directly inhibit tyrosinase activity. As a result, the EU extract and fractions experienced an increase in the tyrosinase inhibitory effect in a dose-dependent manner. In addition, consistent with the above results, EU was most effective at a concentration of $50 \mu \mathrm{g} / \mathrm{mL}$, and the EU fractions had a greater effect than that of the extract. In particular, the concentration of EUBu $(50 \mu \mathrm{g} / \mathrm{mL})$ had more effect than that of arbutin, a positive control.

Next, we investigated the skin-whitening effect of EU extract and fractions on melanogenesis in $\alpha$-MSH-induced B16-F10 melanoma cells. We first used the MTT assay to establish a concentration range at which the EU extract and fractions were non-cytotoxic to B16-F10 cells. Our results confirmed that there was no cytotoxicity in the concentration range of 12.5 to $50 \mu \mathrm{g} / \mathrm{mL}$.

After stimulating B16-F10 cells with $\alpha$-MSH to induce melanin synthesis, the skinwhitening effect of EU extract and fractions on melanin content and intracellular tyrosinase activity was identified. The patterns of EU extract and fractions on melanin con-tent and intracellular tyrosinase activity showed similar results. Treatment with all EU extracts and fractions showed that melanin content and intracellular tyrosinase activity were dosedependently suppressed. In particular, at a concentration of $50 \mu \mathrm{g} / \mathrm{mL}$ of EU fractions, more than $50 \%$ loss of melanin content and intracellular tyrosinase activity was observed compared with that of the $\alpha$-MSH-only stimulated group (Figure 4A,C).

CREB and ERK signaling pathways are major signaling pathways that are activated by the stimulation of $\alpha$-MSH in melanogenesis. Therefore, CREB and ERK, which are involved in various mechanisms, play a key role in the melanin synthesis process. Stimulation of $\alpha$-MSH in B16-F10 melanoma cells increased the expression of MITF and the melanogenesisrelated tyrosinase gene family (TRP-1, TRP-2, and tyrosinase) through the activation of CREB and ERK. In this study, we provide evidence that EU extract and fractions inhibit melanin synthesis as well as the involved upstream signaling pathways, CREB and ERK. 
When the levels of TRP-1 and TRP-2 were increased by up-regulated expression of MITF, the expression of tyrosinase was promoted and the melanogenesis-related enzymes produced melanin [18,32]. The expression of melanogenesis-mediated proteins was observed using western blotting to determine the anti-melanogenic effect of EU extract and fractions in B16-F10 melanoma cells. Our results confirmed that the expression of MITF, TRP-1, TRP-2, and tyrosinase proteins significantly increased in the $\alpha$-MSH-stimulated group. However, treatment with EU extract and fractions down-regulated expression of these melanogenesis-related proteins in a dose-dependent manner. In particular, a significant decrease in expression was observed at a concentration of $50 \mu \mathrm{g} / \mathrm{mL}$ of EU fractions. Our results show that $50 \mu \mathrm{g} / \mathrm{mL}$ of EU fractions inhibited expression of MITF, an important transcription factor, significantly inhibiting tyrosinase expression, and thereby inhibiting melanin production.

Based on these results, we found that $50 \mu \mathrm{g} / \mathrm{mL}$ of EU fractions inhibited the production of $\alpha$-MSH-stimulated melanin production in B16-F10 melanoma cells by downregulating the signaling related to melanogenesis based on the excellent antioxidant effect. Therefore, our results suggest that the EU fraction may be a potential candidate for a whitening treatment that effectively controls melanogenesis.

\title{
5. Conclusions
}

In this study, we evaluated the antioxidant and anti-melanogenic effects on $\alpha$-MSHinduced melanogenesis in B16-F10 melanoma cells to confirm the function of EU fractions as skin-whitening agents. In conclusion, we found that EU fractions have strong antioxidant effects and inhibited melanogenesis-related proteins, such as TRP-1, TRP-2, and tyrosinase, by regulating MITF and are therefore valuable natural inhibitors of melanogenesis. Notably, a concentration $(50 \mu \mathrm{g} / \mathrm{mL})$ of EU extract and fractions was required to inhibit melanin synthesis in $\alpha$-MSH-stimulated B16F10 cells. In addition, we confirmed that EU fractions have superior antioxidant and inhibitory effects on melanin production. Consequently, the EU could be useful for natural-based therapeutic agents for treating skin diseases and as skin-whitening agents in the cosmetics industry.

Author Contributions: Conceptualization, J.-H.L. and D.-K.K.; Data curation, B.L.; Formal analysis, J.-H.L.; Funding acquisition, Y.-M.L.; Investigation, J.-H.L. and Y.-D.J.; Methodology, B.L., H.-W.S. and B.-J.S.; Project administration, Y.-M.L. and D.-K.K.; Software, D.-K.K.; Supervision, Y.-M.L. and D.-K.K.; Visualization, J.-H.L.; Writing—original draft, J.-H.L.; Writing—review \& editing, J.-H.L. and Y.-D.J. All authors have read and agreed to the published version of the manuscript.

Funding: This research was supported by the Ministry of Trade, Industry and Energy (MOTIE), Korea Institute for Advancement of Technology (KIAT) through the Encouragement Program for the Industries of Economic Cooperation Region (P0004749).

Conflicts of Interest: The authors declare that they have no competing interests.

Sample Availability: Samples of the compounds are not available from the authors.

\author{
Abbreviations \\ $\alpha$-MSH $\alpha$-melanocyte stimulating hormone \\ CREB CAMP response element binding protein \\ DOPA 3,4-dihydroxyphenylalanine \\ EU Elaeagnus umbellata \\ EUEE EU 70\% ethanol extract \\ EUEA EU ethyl acetate fraction \\ EUBu EU butanol fraction \\ MC1R melanocyte-specific melanocortin-1 receptor \\ MITF Microphthalmia-associated transcription factor \\ ROS Reactive oxygen species \\ TRP Tyrosinase-related protein
}




\section{References}

1. Desmedt, B.; Courselle, P.; De Beer, J.O.; Rogiers, V.; Grosber, M.; Deconinck, E.; De Paepe, K. Overview of skin whitening agents with an insight into the illegal cosmetic market in Europe. J. Eur. Acad. Dermatol. Venereol. 2016, 30, 943-950. [CrossRef] [PubMed]

2. Costin, G.E.; Hearing, V.J. Human skin pigmentation: Melanocytes modulate skin color in response to stress. Faseb J. 2007, 21, 976-994. [CrossRef]

3. Lin, Y.S.; Wu, W.C.; Lin, S.Y.; Hou, W.C. Glycine hydroxamate inhibits tyrosinase activity and melanin contents through downregulating cAMP/PKA signaling pathways. Amino Acids 2015, 47, 617-625. [CrossRef]

4. Fernandez-Garcia, E. Skin protection against UV light by dietary antioxidants. Food. Funct. 2014, 5, 1994-2003. [CrossRef]

5. Kowalska, J.; Banach, K.; Rok, J.; Beberok, A.; Rzepka, Z.; Wrze'sniok, D. Molecular and Biochemical Basis of FluoroquinolonesInduced Phototoxicity-The Study of Antioxidant System in Human Melanocytes Exposed to UV-A Radiation. Int. J. Mol. Sci. 2020, 21, 9714. [CrossRef] [PubMed]

6. MatÉs, J.M.; Pérez-Gómez, C.; Castro, I.N.D. Antioxidant enzymes and human diseases. Clin. Biochem. 1999, 32, 595-603. [CrossRef]

7. Bickers, D.R.; Athar, M. Oxidative Stress in the Pathogenesis of Skin Disease. J. Investig. Dermatol. 2006, 126, 2565-2575. [CrossRef]

8. Kim, Y.J.; Uyama, H. Tyrosinase inhibitors from natural and synthetic sources: Structure, inhibition mechanism and perspective for the future. Cell. Mol. Life Sci. 2005, 62, 1707-1723. [CrossRef]

9. Pillaiyar, T.; Manickam, M.; Namasivayam, V. Skin whitening agents: Medicinal chemistry perspective of tyrosinase inhibitors. J. Enzyme Inhib. Med. Chem. 2017, 32, 403-425. [CrossRef]

10. Smit, N.; Vicanova, J.; Pavel, S. The hunt for natural skin whitening agents. Int. J. Mol. Sci. 2009, 10, 5326-5349. [CrossRef]

11. Draelos, Z.D. Skin lightening preparations and the hydroquinone controversy. Dermatol. Ther. 2007, 20, 308-313. [CrossRef]

12. Anna, M.I.; Chiara, G.; Marinella, D.L.; Deborah, P.; Fabiano, C.; Nunziatina, D.T.; Claudia, M.; Maria, L.T.; Alessandra, B. Antioxidant activity of compounds isolated from elaeagnus umbellata promotes human gingival fibroblast well-being. J. Nat. Prod. 2020, 83, 626-637.

13. Sabir, S.M.; Dilnawaz, S.; Imtiaz, A.; Hussain, M.; Kaleem, M.T. Antibacterial activity of Elaeagnus umbellata (Thunb.) a medicinal plant from Pakistan. Saudi. Med. J. 2007, 28, 259-263.

14. Nazir, N.; Zahoor, M.; Nisar, M.; Khan, I.; Karim, N.; Abdel-Halim, H.; Ali, A. Phytochemical analysis and antidiabetic potential of Elaeagnus umbellata (Thunb.) in streptozotocin-induced diabetic rats: Pharmacological and computational approach. BMC Complement. Altern. Med. 2018, 18, 332. [CrossRef]

15. Wang, S.Y.; Bowman, L.; Ding, M. Variations in Free Radical Scavenging Capacity and Antiproliferative Activity Among Different Genotypes of Autumn Olive (Elaeagnus umbellata). Planta. Med. 2007, 73, 468-477. [CrossRef] [PubMed]

16. Nazir, N.; Zahoor, M.; Nisar, M.; Karim, N.; Latif, A.; Ahmad, S.; Uddin, Z. Evaluation of neuroprotective and antiamnesic effects of Elaeagnus umbellate Thunb. On scopolamine-induced memory impairment in mice. BMC Complement. Altern. Med. 2020, 20, 143.

17. Park, S.H.; Jhee, K.H.; Yang, S.A. Protective effects of an ethanol extract of elaeagnus umbellata leaves on $\alpha$-MSH-induced melanin production in B16-F0 Cells and UVB-induced damage in CCD-986sk Cells. J. Life Sci. 2019, 29, 555-563.

18. Qian, W.; Liu, W.; Zhu, D.; Cao, Y.; Tang, A.; Gong, G.; Su, H. Natural skin whitening compounds for the treatment of melanogenesis (Review). Exp. Ther. Med. 2020, 20, 173-185. [CrossRef]

19. Gillbro, J.M.; Olsson, M.J. The melanogenesis and mechanisms of skin-lightening agents-existing and new approaches. Int. J. Cosmet. Sci. 2011, 33, 210-221. [CrossRef]

20. Saba, E.; Kim, S.H.; Lee, Y.Y.; Park, C.K.; Oh, J.W.; Kim, T.H.; Kim, H.K.; Roh, S.S.; Rhee, M.H. Korean Red Ginseng extract ameliorates melanogenesis in humans and induces antiphotoaging effects in ultraviolet Beirradiated hairless mice. J. Ginseng. Res. 2020, 44, 496-505. [CrossRef] [PubMed]

21. Bertolotto, C.; Abbe, P.; Hemesath, T.J.; Bille, K.; Fisher, D.E.; Ortonne, J.P.; Ballotti, R. Microphthalmia gene product as a signal transducer in CAMP-induced differentiation of melanocytes. J. Cell. Biol. 1998, 142, 827-835. [CrossRef]

22. Lee, H.J.; Lee, W.J.; Chang, S.E.; Lee, G.Y. Hesperidin, a popular antioxidant inhibits melanogenesis via erk1/2 mediated MITF degradation. Int. J. Mol. Sci. 2015, 16, 18384-18395. [CrossRef]

23. Price, E.R.; Horstmann, M.A.; Wells, A.G.; Weilbaecher, K.N.; Takemoto, C.M.; Landis, M.W.; Fisher, D.E. alpha-Melanocytestimulating hormone signaling regulates expression of microphthalmia, a gene deficient in Waardenburg syndrome. J. Biol. Chem. 1998, 273, 33042-33047. [CrossRef]

24. Vance, K.W.; Goding, C.R. The transcription network regulating melanocyte development and melanoma. Pigment. Cell. Res. 2004, 17, 318-325. [CrossRef]

25. Bondurand, N.; Pingault, V.; Goerich, D.E.; Lemort, N.; Sock, E.; Le Caignec, C.; Wegner, M.; Goossens, M. Interaction among SOX10, PAX3 and MITF, three genes altered in Waardenburg syndrome. Hum. Mol. Genet. 2000, 9, 1907-1917. [CrossRef]

26. McGregor, D. Hydroquinone: An Evaluation of the Human Risks from its Carcinogenic and Mutagenic Properties. Crit. Rev. Toxicol. 2007, 37, 887-914. [CrossRef]

27. Kolbe, L.; Kligman, A.M.; Schreiner, V.; Stoudemayer, T. Corticosteroid-induced atrophy and barrier impairment measured by non-invasive methods in human skin. Skin. Res. Technol. 2001, 7, 73-77. [CrossRef] [PubMed]

28. Huang, H.C.; Chang, S.J.; Wu, C.Y.; Ke, H.J.; Chang, T.M. [6]-Shogaol inhibits $\alpha$-MSH-induced melanogenesis through the acceleration of ERK and PI3K/Akt-mediated MITF degradation. Biomed. Res. Int. 2014, 2014, 842569. [CrossRef] 
29. Ozen, T.; Yenigun, S.; Altun, M.; Demirtas, I. Phytochemical Constituents, ChEs and Urease Inhibitions, Antiproliferative and Antioxidant Properties of Elaeagnus umbellata Thunb. Comb. Chem. High. Throughput. Screen. 2017, 20, 559-578. [CrossRef]

30. Floegel, A.; Kim, D.O.; Chung, S.J.; Koo, S.I.; Chun, O.K. Comparison of ABTS/DPPH assays to measure antioxidant capacity in popular antioxidant-rich US foods. J. Food Compos. Anal. 2011, 24, 1043-1048. [CrossRef]

31. Hseu, Y.C.; Chen, X.Z.; Gowrisankar, Y.V.; Yen, H.R.; Chuang, J.Y.; Yang, H.L. The Skin-Whitening Effects of Ectoine via the Suppression of $\alpha$-MSH-Stimulated Melanogenesis and the Activation of Antioxidant Nrf2 Pathways in UVA-Irradiated Keratinocytes. Antioxidants 2020, 9, 63. [CrossRef] [PubMed]

32. Jang, E.J.; Shin, Y.; Park, H.J.; Kim, D.; Jung, C.; Hong, J.Y.; Kim, S.; Lee, S.K. Anti-melanogenic activity of phytosphingosine via the modulation of the microphthalmia-associated transcription factor signaling pathway. J. Dermatol. Sci. 2017, 87, 19-28. [CrossRef] [PubMed] 